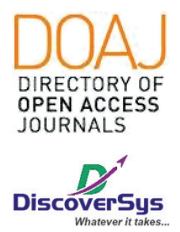

Published by DiscoverSys

\section{Analisis faktor - faktor yang mempengaruhi kejadian Malnutrisi Rumah Sakit (MRS) pada pasien anak di Bangsal Kaswari, RSUD Wangaya, Bali, Indonesia}

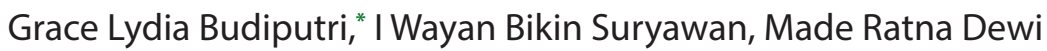

\section{ABSTRACT}

Background: Hospital malnutrition (MRS) is malnutrition that occurs during hospitalization. The incidence of hospital malnutrition is still high in both developed and developing countries. Hospital malnutrition has a significant impact on mortality and increases the risk of children developing complications. Therefore this study aims to analyze the factors that influence the incidence of MRS in pediatric patients in Kaswari Ward, Wangaya Hospital, Bali, Indonesia.

Methods: This prospective cohort study was conducted on 110 pediatric patients who were treated in the Kaswari Ward, Wangaya Hospital, Denpasar City, aged 1 month to 17 years in July-September 2019 using the consecutive technique. The diagnosis of MRS is confirmed if there is weight loss $>2 \%$ in children treated $>48$ hours to 7 days or weight loss in children treated 8 to 30 days. Data were analyzed using SPSS version 20 for Windows.

Results: The results showed that most of the respondents aged 324 months (23.6\%), male gender (55.5\%), had a history of GEA disease (35.5\%), nutritional status > -2SD WHZ (77.3\%), had a single diagnosis (35.5\%), and length of stay ranged from 4-7 days (60.0\%). Multivariate analysis showed that the nutritional status at admission to the hospital (RR: 4,$155 ; 95 \% \mathrm{Cl}: 1,289-13,392 ; \mathrm{p}=0.017)$ and length of stay was more than 7 days (RR: 8,219; 95\% Cl 1,643-41,098; $p=0,01$ ) has a significant relationship with the incidence of MRS. However, the number of diagnoses did not have a significant relationship with the incidence of MRS ( $p>0.05$ ). Conclusion: This study shows that children who are treated with a length of stay of more than 7 days are more at risk of experiencing MRS.

Keywords: Hospital Malnutrition, Nutritional Status, Factor Analysis

Cite This Article: Budiputri, G.L., Suryawan, I.W.B., Dewi, M.R. Analisis faktor - faktor yang mempengaruhi kejadian Malnutrisi Rumah Sakit (MRS) pada pasien anak di Bangsal Kaswari, RSUD Wangaya, Bali, Indonesia. Intisari Sains Medis 11(2): 680-685. D0I: 10.15562/ism.v11i2.647

Latar Belakang: Malnutrisi Rumah Sakit (MRS) merupakan malnutrisi yang terjadi pada selama perawatan di rumah sakit. Angka kejadian Malnutri Rumah Sakit masih tinggi baik di negara maju maupun berkembang. Malnutrisi Rumah Sakit memiliki dampak yang signifikan pada angka mortalitas dan peningkatan resiko anak mengalami komplikasi. Oleh karena itu penelitian ini bertujuan untuk menganalisis faktor - faktor yang mempengaruhi kejadian MRS pada pasien anak di Bangsal Kaswari, RSUD Wangaya, Bali, Indonesia.

Metode: Penelitian kohort prospektif dilakukan pada 110 pasien anak yang di rawat di Bangsal Kaswari RSUD Wangaya kota Denpasar dengan usia 1 bulan hingga 17 tahun pada bulan Juli-September 2019 dengan teknik konsekutif. Diagnosis MRS ditegakkan apabila terjadi penurunan berat badan $>2 \%$ pada anak yang dirawat $>48$ jam sampai 7 hari atau penurunan berat badan pada anak yang dirawat 8 sampai 30 hari. Data dianalisis dengan SPSS versi 20 untuk Windows.

Hasil: Hasil penelitian menunjukkan bahwa sebagian besar responden berusia 3-24 bulan (23,6\%), jenis kelamin laki-laki $(55,5 \%)$, memiliki riwayat penyakit GEA (35,5\%), status gizi >-2SD WHZ (77,3\%), memiliki diagnosis tunggal $(35,5 \%)$, dan lama rawat inap berkisar 4-7 hari $(60,0 \%)$. Analisis multivariat menunjukkan bahwa status gizi saat masuk rumah sakit (RR: 4,155; 95\% IK: 1,289-13,392; $p=0,017$ ) dan lama perawatan lebih dari 7 hari (RR: 8,219; 95\% IK 1,643-41,098; $\mathrm{p}=0,01$ ) memiliki hubungan bermakna dengan kejadian MRS. Akan tetapi, jumlah diagnosis tidak memiliki hubungan yang bermakna dengan kejadian MRS $(p>0,05)$.

Kesimpulan: Studi ini menunjukkan bahwa anak yang dirawat dengan lama perawatan lebih dari 7 hari lebih beresiko untuk mengalami kejadian MRS. 


\section{PENDAHULUAN}

Pada saat seorang anak sakit, maka kebutuhan nutrisi yang diperlukan juga meningkat sehingga setiap anak yang dirawat di rumah sakit beresiko mengalami malnutrisi rumah sakit. ${ }^{1}$ Namun seringkali anak yang dirawat dirumah sakit beresiko terhadap kejadian malnutrisi rumah sakit yang disebabkan oleh adanya penurunan asupan makan, hipermetabolisme, malabsorbsi, dan kehilangan nutrisi. ${ }^{1,2}$ Penyakit, perubahan lingkungan rumah sakit, berbagai prosedur tindakan medis, dan stress akibat jauh dari keluarga dapat menimbulkan stress pada anak yang dirawat di rumah sakit. ${ }^{2} \mathrm{Hal}$ ini akan mengakibatkan keinginan untuk makan berkurang sehingga asupan nutrisi juga menurun. Sedangkan pada saat sakit, nutrisi yang dibutuhkan akan meningkat untuk melawan penyebab sakit. ${ }^{3}$ Oleh sebab itu, asupan nutrisi yang tidak optimal dapat menyebabkan terjadinya malnutrisi rumah sakit. ${ }^{2,3}$

Malnutrisi rumah sakit merupakan malnutrisi yang terjadi pada selama perawatan di rumah sakit. ${ }^{2,3}$ Malnutrisi ini akan memiliki hubungan yang erat dengan waktu perawatan lebih lama, pemulihan fungsional yang lebih lama, meningkatnya komplikasi penyakit, dan angka morbiditas serta mortalitas yang lebih tinggi. ${ }^{1-3}$ Pada anak yang dirawat dan mengalami malnutrisi rumah sakit memiliki resiko 1,6 kali mengalami komplikasi penyakit dibandingkan dengan anak yang tidak malnutrisi rumah sakit. ${ }^{2,3}$ Sedangkan angka mortalitas pasien dengan malnutrisi rumah sakit meningkat sebesar 3 kali apabila dibandingkan dengan pasien tanpa malnutrisi rumah sakit. ${ }^{1,2}$ Selain itu, malnutrisi rumah sakit berdampak terjadinya peningkatan biaya rumah sakit sebesar 3 kali lipat dan lama perawatan di rumah sakit memanjang sebesar 1,5 - 2 kali lipat. ${ }^{2}$

Berdasarkan penelitian yang ada, disebutkan bahwa insidensi terjadinya malnutrisi rumah sakit di negara maju sekitar $6,1 \%$ hingga $11 \%$, sedangkan di negara berkembang memiliki angka insiden yang lebih tinggi, yaitu 6,9\% hingga 53\%. ${ }^{4}$ Pada penelitian yang dilakukan pada RSUP dr. Sardjito, Yogyakarta didapatkan sebesar 27\% pasien anak mengalami malnutrisi rumah sakit dengan faktor prediktor yang berpengaruh adalah derajat penyakit yang diderita. ${ }^{2}$ Sebesar 70\% malnutrisi rumah sakit tidak terdiagnosa dan tidak mendapatkan tatalaksana hingga pasien keluar dari rumah sakit. Ada beberapa faktor yang dapat mempengaruhi terjadinya malnutrisi rumah sakit, dimana dapat dibagi menjadi faktor yang berkaitan dengan penyakit yang diderita dan faktor yang tidak berkaitan dengan penyakit pasien. ${ }^{1,2}$ Dengan mengetahui faktor penyebab malnutrisi rumah sakit, maka dapat dilakukan pencegahan dengan memberikan tatalaksana nutrisi yang baik selama dalam perawatan dan penanganan intervensi nutrisi secepatnya. ${ }^{5}$ Berkaitan dengan hal tersebut, maka penelitian ini bertujuan untuk menganalisis faktor - faktor yang mempengaruhi kejadian Malnutrisi Rumah Sakit (MRS) pada pasien anak di Bangsal Kaswari, RSUD Wangaya, Bali, Indonesia.

\section{METODE}

Jenis penelitian yang digunakan adalah dengan rancangan kohort prospektif. Penelitian ini berlangsung sejak Juli 2019 hingga September 2019 dengan melibatkan 114 pasien. 4 pasien loss to follow up dikarenaka pulang atas permintaan sendiri. Kriteria inklusi subyek yang diteliti adalah pasien baru berusia 1 bulan hingga 17 tahun dengan minimal lama perawatan 48 jam yang dapat dilakukan pengukuran berat badan dan tinggi badan. Subyek yang tidak dapat diikutkan dalam penelitian ini adalah pasien yang dirawat dengan adanya retensi cairan (edema, asites, hidrosefalus), massa atau tumor yang jelas, obesitas, dan organomegali dikarenakan akan mempengaruhi pengukuran berat badan. Pasien pindah ke ruang perawatan lain dan tidak kembali ke ruangan Kaswari RSUD Wangaya, Denpasar, pasien yang meninggal, dan pasien yang pulang atas permintaan sendiri sebelum dinyatakan sembuh dinyatakan loss to follow up.

Diagnosis Malnutrisi Rumah Sakit (MRS) ditegakkan apabila terjadi penurunan berat badan $>2 \%$ dalam perawatan $<7$ hari atau 5\% dalam perawatan 8 - 30 hari. Pengukuran berat badan untuk anak berusia kurang dari 1 tahun menggunakan timbangan digital (baby scale) merk Seca dalam satuan gram dan untuk anak yang berusia lebih dari 1 tahun atau sudah dapat berdiri tegak tanpa dipegangi menggunakan tumbangan digital merek Camry dengan ketepatan 0,5 kg. Pengukuran untuk anak dengan usia minimal >1tahun dilakukan dalam busana minimal. Sedangkan untuk anak yang berusia $<1$ tahun maka pengukuran dilakukan dalam kondisi tanpa busana. Berat badan diukur pada saat anak pertama kali masuk ke ruang perawatan dan pada saat pasien akan dipulangkan.

Status Gizi saat masuk rumah sakit dinilai dengan menggunakan kurva WHO weight for length atau wight for height untuk anak berusia $<5$ tahun. ${ }^{10,11}$ Untuk anak berusia lebih dari 5 tahun akan digunakan kurva CDC dan diklasifikasikan berdasarkan klasifikasi Waterlow. Lama pasien dirawat dihitung dari selisih antara tanggal masuk dan tanggal pulang dari rumah sakit. Jumlah diagnosis akan dilihat dalam 48 jam perawatan apakah 
ditemui diagnosis utama lebih dari 1 untuk disebut diagnosis multipel. Selan itu, akan dilakukan pencatatan mengenai usia, jenis kelamin, dan jenis penyakit pasien. Seluruh data yang terkumpul akan dilakukan pengolahan data dengan SPSS versi 20 untuk Windows. Analisis data bivariat dilakukan dengan menggunakan metode Chi Square. Variabel yang memiliki $\mathrm{p}<0,25$ pada analisis bivariat akan dimasukkan ke dalam analisis multivariat.

\section{HASIL}

Pada penelitian ini didapatkan 41 anak dari total 110 sampel ditemukan mengalami Malnutrisi
Rumah Sakit (37,0\%). Jumlah sampel terdiri dari $61(55,5 \%)$ laki-laki dan 49 (45,5\%) perempuan (Tabel 1). Kelompok usia terbanyak adalah anak dengan usia $>60$ bulan, yaitu sebanyak 34 anak $(31,0 \%)$. Status gizi pada saat anak masuk rumah sakit adalah gizi baik atau lebih, sebesar 77,3\% atau sebanyak 85 anak. Alasan anak dirawat paling banyak disebabkan oleh gastroenteritis akut $(35,0 \%)$ (Tabel 1). Prevalensi malnutrisi rumah sakit lebih tinggi ditemukan pada anak laki-laki dibandingkan dengan anak perempuan. Anak yang berusia $>60$ bulan memiliki insiden malnutrisi rumah sakit lebih tinggi (36,6\%) dibandingkan dengan anak berusia 1-12 bulan (12,2\%) (Tabel 1).

Tabel 1 Karakteristik Dasar Pasien

\begin{tabular}{|c|c|c|c|}
\hline \multirow[b]{2}{*}{ Karakteristik } & \multicolumn{2}{|c|}{ Malnutrisi Rumah Sakit ( $\mathrm{N}=110)$} & \multirow[b]{2}{*}{ Total } \\
\hline & $\mathrm{Ya}(\mathrm{N}=41)$ & Tidak $(\mathrm{N}=69)$ & \\
\hline \multicolumn{4}{|l|}{ Usia (bulan), n (\%) } \\
\hline $1-12$ & $5(12,2)$ & $20(29,0)$ & $25(22,7)$ \\
\hline $3-24$ & $10(24,3)$ & $16(23,2)$ & $26(23,6)$ \\
\hline $25-60$ & $11(26,8)$ & $14(20,3)$ & $25(22,7)$ \\
\hline$>60$ & $15(36,6)$ & $19(27,5)$ & $34(31,0)$ \\
\hline \multicolumn{4}{|l|}{ Jenis Kelamin, n (\%) } \\
\hline Laki-laki & $28(68,3)$ & $33(47,8)$ & $61(55,5)$ \\
\hline Perempuan & $13(31,7)$ & $36(52,2)$ & $49(45,5)$ \\
\hline \multicolumn{4}{|l|}{ Jenis Penyakit, n (\%) } \\
\hline GEA & $10(24,3)$ & $29(42,0)$ & $39(35,5)$ \\
\hline Asma & $0(0,0)$ & $3(4,3)$ & $3(2,7)$ \\
\hline Kejang Demam & $5(12,2)$ & $5(7,2)$ & $10(9,1)$ \\
\hline $\mathrm{BP}$ & $5(12,2)$ & $2(3,0)$ & $7(6,4)$ \\
\hline $\mathrm{DD} / \mathrm{DBD}$ & $10(24,3)$ & $9(13,0)$ & $19(17,3)$ \\
\hline $\mathrm{GEA}+\mathrm{KD}$ & $0(0,0)$ & $1(1,5)$ & $1(0,9)$ \\
\hline GEA + Asma & $1(2,5)$ & $0(0,0)$ & $1(0,9)$ \\
\hline $\mathrm{GEA}+\mathrm{DB}$ & $3(7,4)$ & $1(1,5)$ & $4(3,6)$ \\
\hline $\mathrm{GEA}+\mathrm{BP}$ & $2(4,9)$ & $0(0,0)$ & $2(1,8)$ \\
\hline Lain-lain ${ }^{*}$ & $5(12,2)$ & $19(27,5)$ & $24(21,8)$ \\
\hline \multicolumn{4}{|l|}{ Status Gizi, n (\%) } \\
\hline$>-2 \mathrm{SD} \mathrm{WHZ}^{\star} />90 \% \mathrm{CDC}^{\star *}$ & $26(63,4)$ & $59(85,6)$ & $85(77,3)$ \\
\hline$<-2 \mathrm{SD} \mathrm{WHZ}^{\star} /<90 \% \mathrm{CDC}^{\star *}$ & $15(36,6)$ & $10(14,4)$ & $25(22,7)$ \\
\hline \multicolumn{4}{|l|}{ Jumlah Diagnosis, n (\%) } \\
\hline Tuggal & $18(43,9)$ & $53(76,8)$ & $71(64,5)$ \\
\hline Multipel & $23(56,1)$ & $16(23,2)$ & $39(35,5)$ \\
\hline \multicolumn{4}{|l|}{ Lama Rawat Inap (hari), n (\%) } \\
\hline $2-3$ & $3(7,4)$ & $26(37,7)$ & $29(26,3)$ \\
\hline $4-7$ & $25(60,9)$ & $41(59,5)$ & $66(60,0)$ \\
\hline$>7$ & $13(31,7)$ & $2(2,8)$ & $15(13,7)$ \\
\hline
\end{tabular}

\#)termasuk didalamnya adalah epilepsi, bronkiolitis, campak, roseola infantum, tonsillitis kronis dengan hiperleukositosis, herpes zoster, dan varicella zoster; ${ }^{*}$ )Weight for height atau weight for length kurva WHO; $\left.{ }^{*}\right)$ Kurva Centers for Disease Control and Prevention dan diklasifikasikan berdasarkan Waterlow classification 
Tabel 2 Hasil analisis bivariat dan multivariat faktor yang berhubungan dengan MRS

\begin{tabular}{|c|c|c|c|c|c|c|c|}
\hline \multirow[b]{2}{*}{ Variabel } & \multirow[b]{2}{*}{$\mathbf{N}$} & \multicolumn{3}{|c|}{ Bivariat } & \multicolumn{3}{|c|}{ Multivariat } \\
\hline & & $\mathbf{R} \mathbf{R}$ & 95\% IK & $\mathbf{p}$ & $\mathbf{R R}$ & $95 \%$ IK & $\mathbf{p}$ \\
\hline \multicolumn{8}{|l|}{ Status Gizi } \\
\hline$>-2 \mathrm{SD} W H Z / \mathrm{L}^{\star} />90 \% \mathrm{CDC}^{\star *}$ & $85(77,3 \%)$ & 1,962 & $1,247-3,085$ & 0,008 & 4,155 & $1,289-13.392$ & 0,017 \\
\hline$<-2 \mathrm{SD} W H Z / \mathrm{L}^{\star} /<90 \% \mathrm{CDC}^{\star *}$ & $25(22,7 \%)$ & & & & & & \\
\hline \multicolumn{8}{|l|}{ Jumlah Diagnosis } \\
\hline Tuggal & $71(64,5 \%)$ & 2,326 & $1,443-3,749$ & 0,000 & 0,135 & $0,033-0,546$ & 0,005 \\
\hline Multipel & $39(35,5 \%)$ & & & & & & \\
\hline \multicolumn{8}{|l|}{ Lama Rawat Inap (hari) } \\
\hline $2-3$ & $29(26,3 \%)$ & 0,221 & $0,074-0,660$ & 0,000 & 8,219 & $1,643-41,098$ & 0,010 \\
\hline $4-7$ & $66(60 \%)$ & 1,042 & $0,633-1,714$ & 0,872 & & & \\
\hline$>7$ & $15(13,7 \%)$ & 2,940 & $2,033-4,253$ & 0,000 & & & \\
\hline
\end{tabular}

*) Weight for height atau weight for length kurva WHO; $\left.{ }^{* *}\right)$ Kurva Centers for Disease Control and Prevention dan diklasifikasikan berdasarkan Waterlow classification; IK: interval kepercayaan; RR: resiko relatif.

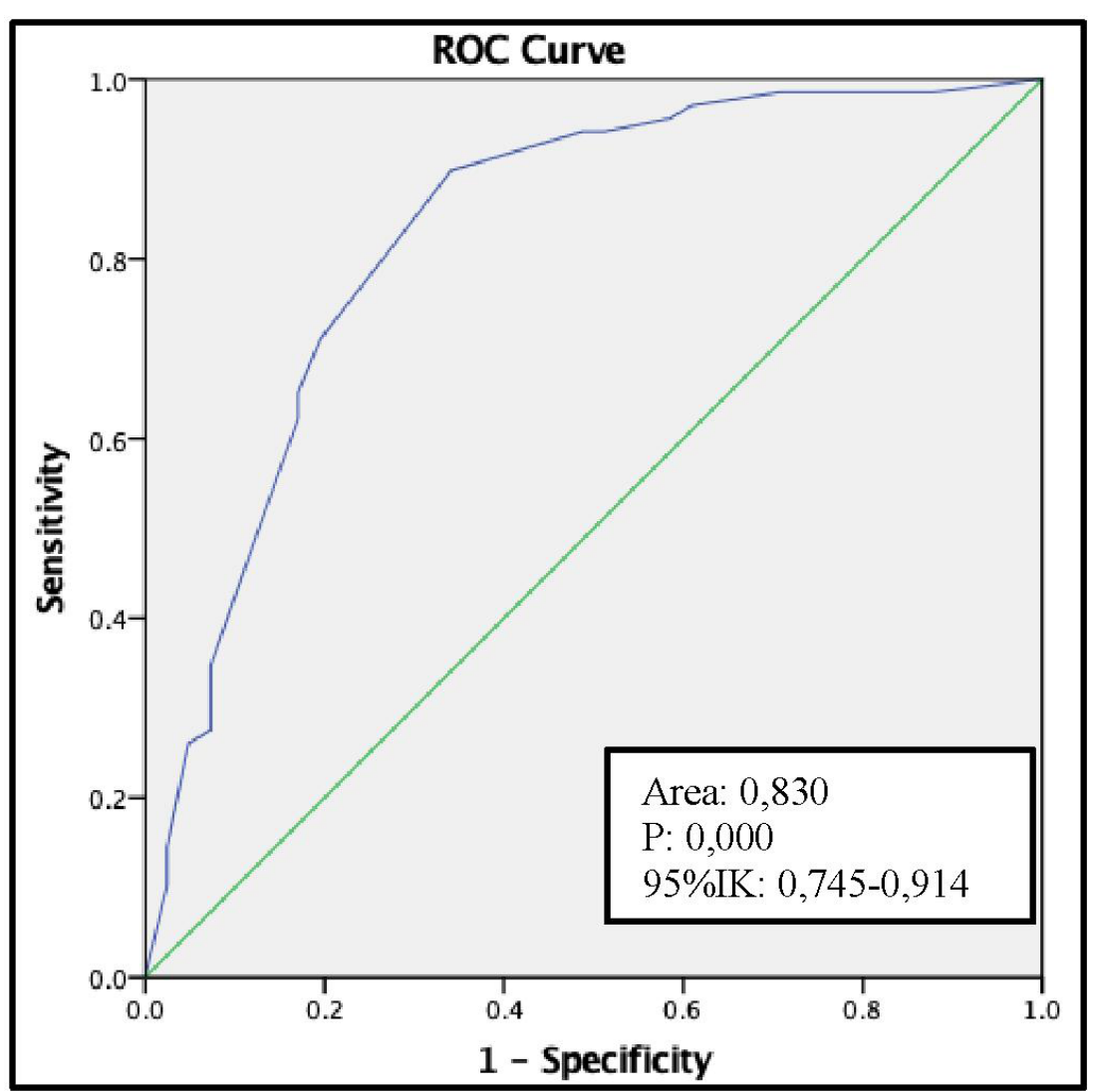

Gambar 1 Area Under the Curve (AUC) antara lama rawat dengan kejadian MRS
CDC (Tabel 2). Sedangkan lama rawat inap juga sangat mempengaruhi kejadian malnutrisi rumah sakit dimana anak yang dirawat kurang dari 3 hari meiliki resiko yang lebih rendah untuk mengalami malnutrisi rumah sakit, berbanding terbalik dengan anak yang dirawat lebih dari 7 hari (Tabel 2).

Setelah dilakukan analisis multivariat, maka dapat dilihat bahwa faktor resiko yang akan mempengaruhi malnutrisi rumah sakit secara signifikan adalah lama rawat inap lebih dari 7 hari (RR: 8,219; 95\%IK: 1,643-41,098; $\mathrm{p}=0,010$ ) dan status gizi saat masuk (RR:4,155; 95\% IK:1,289-13,392; p=0,017) (Tabel 3). Sedangkan hasil analisis Receiver Operating Curve (ROC) menunjukkan bahwa terdapat nilai AUC yang bermakna secara statistik $(0,830 ; \mathrm{p}=0,000)$ antara lama rawat dengan kejadian MRS (Gambar 1).

\section{PEMBAHASAN}

Pada penelitian ini didapatkan angka kejadian Malnutrisi Rumah Sakit di RSUD Wangaya kota Denpasar sebesar 37\%, dimana termasuk tinggi. Hal ini tidak berbeda jauh dengan penelitian yang dilakukan oleh Maryani dkk sebesar 27\% di RSUP dr. Sardjito Yogyakarta dan Sidiartha di RSUP Sanglah sebesar 30\%., ${ }^{2,3}$ Pada penelitian ini didapatkan apabila anak dirawat dengan status gizi saat masuk ke perawatan berada <-2SD WHZ/L atau $<90 \%$ CDC beresiko untuk terkena malnutrisi rumah sakit sebesar 4,15 kali dibandingkan dengan pasien yang status gizi >-2SD WHZ/L atau $>90 \%$ CDC. Kejadian malnutrisi rumah sakit juga berhubungan erat dengan lama perawatan dimana pada anak yang dirawat lebih dari 7 hari memiliki resiko yang bertambah sebesar 8 kali lipat dibandingkan pada anak yang dirawat kurang dari 7 hari. Pada anak yang dirawat kurang dari 3 hari, maka 
resiko untuk mengalami malnutrisi rumah sakit juga turun.

Anak yang pada saat masuk rumah sakit memiliki status gizi yang kurang atau buruk maka lebih beresiko untuk mengalami malnutrisi rumah sakit. Pada penelitian yang dilakukan oleh Groleau didapatkan bahwa status gizi saat pasien masuk akan mempengaruhi lama perawatan. ${ }^{6}$ Hal ini juga berkaitan dengan kurangnya gizi yang dibutuhkan anak untuk penyembuhan. Oleh sebab itu, pada anak yang mengalami gizi kurang dan gizi buruk dapat berakibat pada lamanya penyembuhan sehingga dapat berdampak kepada kejadian malnutrisi rumah sakit. ${ }^{6}$ Gizi yang kurang atau buruk adalah suatu keadaan kronis dimana hal ini menyebabkan anak menjadi rentan untuk terkena penyakit sehingga dapat menimbulkan komplikasi yang menyebabkan kebutuhan energi meningkat. ${ }^{6,7}$ Kebutuhan energi yang meningkat pada anak yang sedang sakit akan menjadi sangat kurang pada anak yang sejak awalnya memiliki modal gizi yang kurang atau buruk. ${ }^{2}$ Pada beberapa pasien yang derajat penyakitnya berat atau penyakit yang diderita adalah penyakit kronis yang mengalami perburukan atau penyakit berat yang pada episode akut, maka membutuhkan energi lebih banyak lagi.

Pada penelitian ini dapat dilihat bahwa anak yang lebih lama di rawat dapat menjadi faktor yang menyebabkan terjadinya malnutrisi rumah sakit. $\mathrm{Hal}$ ini sejalan dengan penelitian yang dilakukan oleh Sidiartha. ${ }^{3}$ Semakin lama anak dirawat, maka lingkungan rumah sakit yang tidak nyaman bagi anak dan berbagai prosedur tindakan medis yang menyebabkan anak stress akan semakin dapat menimbulkan kurangnya nafsu makan dan asupan makan anak. Anak yang susah bertemu dengan keluarganya akibat di rawat di rumah sakit juga dapat mengalami penurunan nafsu makan. ${ }^{3}$ Selain itu, semakin lama anak terpapar dengan lingkungan rumah sakit, maka resiko anak untuk terkena infeksi nosokomial juga akan semakin tinggi. Anak yang dirawat lebih lama secara umum memiliki diagnosis yang lebih kompleks sehigga resiko untuk mengalami malnutrisi rumah sakit yang diakibatkan peningkatan kebutuhan asupan, pemakaian energi untuk penyembuha, nafsu makan yang berkurang, serta penyakit yang kronis. ${ }^{6,7}$ Pada penelitian ini terlihat bahwa $80 \%$ anak yang dirawat lebih dari 7 hari memiliki diagnosis lebih dari 1 . Namun, jumlah diagnosis pada saat masuk rumah sakit ditemukan tidak ada hubungannya dengan kejadian malnutrisi rumah sakit. Hal ini juga sesuai dengan penelitian sebelumnya yang dilakukan oleh Maryani E et al sebelumnya. ${ }^{2}$

Kekurangan pada penelitian ini adalah tidak dilakukan penilaian antara derajat penyakit dengan kejadian malnutrisi rumah sakit. Derajat penyakit merupakan salah satu faktor yang dapat mempengaruhi kejadian malnutrisi rumah sakit dikarenakan hal ini berhubungan dengan asupan makanan, peningkatan kebutuhan energi, perubahan metabolisme, dan adanya malabosrbsi. ${ }^{2}$ Oleh sebab itu, derajat penyakit dapat diperhitungkan untuk diteliti pada penelitian berikutnya. Pada penelitian selanjutnya mungkin juga dapat dilakukan pengukuran terhadap kadar albumin dan CRP untuk melihat hubungannya dengan derajat penyakit yang dapat mempengaruhi kejadian malnutrisi rumah sakit. Selain itu, tidak dilakukan penilikan asupan makanan pasien saat dirawat sehingga tidak dapat dilihat apakah hal tersebut bermakna atau tidak pada kejadian malnutrisi rumah sakit.

Oleh karena malnutrisi rumah sakit pada anak yang di rawat inap memerlukan perhatian yang khusus, maka harus dipertimbangkan pemberian tatalaksana secara multidisiplin., ${ }^{78}$ Kejadian malnutrisi rumah sakit memiliki hubungan yang erat dengan dukungan nutrisi selama perawatan, sehingga malnutrisi rumah sakit dapat dicegah dengan memberikan tatalaksana nutrisi yang baik selama perawatan di rumah sakit. ${ }^{3,9}$ Selain itu, pada pasien dengan status gizi kurang atau buruk pada saat masuk rumah sakit, serta pasein yang diprediksi akan mendapatkan perawatn yang lama dapat lebih diperhatikan kebutuhan gizi nya. ${ }^{7,8}$ Dapat pula diterapkan skrining untuk malnutrisi rumah sakit dengan menggunakan Simple Pediatric Nutritional Risk Score juga dapat diterapkan pada setiap pasien untuk menilai apakah pasien beresiko untuk mengalami malnutrisi atau tidak sehingga dapat dketahui kapan harus diberikan intervensi nutrisi pada tiap pasien. ${ }^{9,10}$ Asuhan nutrisi di rumah sakit dapat dilakukan dengan cara membuat diagnosis masalah nutrisi, menentukan kebutuhan nutrisi, menentukan alternatif ccara atau rute pemberian sesuai dengan kebutuhan pasien, menentukan jenis makanan yang sesuai dengan alternatif sediaan gizi, melaksanakan pemberian makan atau diet atau dukungan nutrisi, dan evaluasi serta pengkajian respon. ${ }^{7,9}$

\section{KONFLIK KEPENTINGAN}

Tidak ada konflik kepentingan pada penelitian ini.

\section{PERSETUJUAN ETIK}

Penelitian ini telah mendapatkan persetujuan dari komite etik dan penelitian kesehatan RSUD Wangaya kota Denpasar sebelum penelitian berjalan. 


\section{PENDANAAN}

Tidak ada sumber pendanaan lain selain peneliti dalam penelitian ini.

\section{KONTRIBUSI PENULIS}

Seluruh penulis berkontribusi terhadap penulisan laporan penelitian ini baik dari tahap penyusunan kerangka penelitian, pengumpulan data, analisis data, hingga interpretasi data penelitian dalam bentuk publikasi ilmiah.

\section{DAFTAR PUSTAKA}

1. Nesal NNM, Sidiartha GL, Prawirohartono EP, Suandi KG. Accuracy of modified simple pediatric nutritional risk score to detect in-hospital malnutrition. Paediatrica Indonesiana. 2010;50(5):305-309.

2. Maryani E, Prawirohartono EP, Nugroho S. Faktor Prediktor Malnutrisi Rumah Sakit pada Anak. Sari Pediatri. 2017;18(4):278-284.

3. Sidiartha IGL. Insidens Malnutrisi Rawat Inap pada Anak Balita di Rumah Sakit Umum Pusat Sanglah Denpasar. Sari Pediatri. 2008;9(6):381-385.

4. Juliaty A. Malnutrisi Rumah Sakit Pada Bangsal Anak Rumah Sakit Dr. Wahidin Sudirohusodo Makassar. Sari Pediatri 2013;15(2):65-68.
5. Moreno Villares JM, Varea Calderón V, Bousoño García C; en nombre de la Sociedad Española de Gastroenterología, Hepatología y Nutrición Pediátrica (SEGHNP). Malnutrition in children admitted to hospital. Results of a national survey. An Pediatr (Barc). 2017;86(5):270-276.

6. Groleau V, Thibault M, Doyon M, Brochu EE, Roy CC, Babakissa C. Malnutrition in hospitalized children: prevalence, impact, and management. Can J Diet Pract Res. 2014;75(1):29-34.

7. Löser C. Malnutrition in hospital: the clinical and economic implications. Dtsch Arztebl Int. 2010;107(51-52):911-917.

8. Besora-Moreno M, Llauradó E, Tarro L, Solà R. Social and Economic Factors and Malnutrition or the Risk of Malnutrition in the Elderly: A Systematic Review and Meta-Analysis of Observational Studies. Nutrients. 2020;12(3):737.

9. Sermet-Gaudelus I, Poisson-Salomon AS, Colomb V, Brusset MC, Mosser F, Berrier F, et al. Simple pediatric nutritional risk score to identify children at risk of malnutrition. Am J Clin Nutr. 2000;72(1):64-70.

10. Ekawanti A, Irawati D, Lestarini IA, Cholidah R. Effect of iodine status on nutritional status of school-age children in artisanal and small scale gold mining area. Bali Medical Journal. 2019;8(3):764-768.

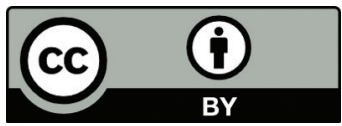

This work is licensed under a Creative Commons Attribution 